\title{
The Assessment of the Patient Safety Culture Based on the Safety Attitudes Questionnaire in a State-Owned Regional Hospital in Taiwan
}

\author{
Hsin-Hung $\mathrm{Wu}^{1,2}$, Jiunn-I Shieh ${ }^{2,3}$, Kuan-Kai Huang ${ }^{4}$, Wen-Huai Hsieh ${ }^{5}$, Shuo-Yen Ting6, Jy-Wun \\ Chen $^{7}$ \\ ${ }^{1}$ Department of Business Administration, National Changhua University of Education, Changhua City, \\ Taiwan. \\ 2 Department of M-Commerce and Multimedia Applications, Asia University, Taichung City, Taiwan. \\ ${ }^{3}$ Department of Dental Hygiene, China Medical University, Taichung City, Taiwan. \\ ${ }^{4}$ Center for Quality Management, Chang Hua Hospital, Changhua County, Taiwan. \\ ${ }^{5}$ Superintendent Office, Chang Hua Hospital, Changhua County, Taiwan. \\ ${ }^{6}$ Department of Psychiatry, Chang Hua Hospital, Changhua County, Taiwan. \\ ${ }^{7}$ Center for Quality Management, Chang Hua Hospital, Changhua County, Taiwan. \\ *Corresponding author. Tel.: 0938-257-327; email:hydokykk@gmail.com \\ Manuscript submitted March 15, 2017; accepted July 15, 2017. \\ doi: 10.17706/ijeeee.2017.7.4.272-279
}

\begin{abstract}
The patient safety culture based on the safety attitudes questionnaire from a state-owned regional teaching hospital in Taiwan is analyzed in terms of six dimensions by independent sample t test and one-way analysis of variance from the viewpoints of physicians and nurses. Gender, age, job position, job status, and education are critical demographic variables that have significant impacts on five out of six dimensions. In contrast, teamwork climate, safety climate, job satisfaction, and perceptions of management are the critical dimensions because they are statistically influenced by six out of nine demographic variables. To relentlessly improve the patient safety culture in this regional hospital, the hospital management needs to pay much attention to critical demographic variables, identify those employees with statistically lower perceptions in terms of dimensions, and then take actions to address their deficiencies.
\end{abstract}

Key words: Patient safety culture, safety attitudes questionnaire, state-owned regional hospital, analysis of variance, demographic variable.

\section{Introduction}

Patient safety has become a great concern throughout the world particularly in healthcare organizations [1]-[3]. A positive patient safety culture in healthcare organizations improves patient safety performance and safety outcomes [1], [4]. More importantly, it indicates that organizations strive to improve patient safety relentlessly and place the patient safety culture as one of their highest priorities [2]. Furthermore, Aghdash et al. [5] summarized that patient safety, which is a critical element for healthcare organizations, should be assessed on a regular basis to improve patient safety.

Bodur and Filiz [6] suggested that the patient safety culture can be evaluated from the perceptions of healthcare organizations' staffs on issues such as teamwork, job satisfaction, and working condition. Chen and Li [4] emphasized that the culture of healthcare organizations should be assessed in order to improve patient safety within the healthcare processes. Based on the assessment results, healthcare organizations 
can identify specific requirements to strengthen their patient safety culture and then make comparisons with other healthcare organizations [2]. Safety attitudes questionnaire (SAQ) originally developed by Sexton et al. [7] has been widely used to assess the safety culture of healthcare organizations [8]-[10]. Staffing deficiencies can be found and the strengths can also be identified through the SAQ surveys [11].

Lee et al. [2] pointed out that nurses' attitudes toward the patient safety culture is critically important because they have contacts and close relationships with patients in healthcare organizations. Lee et al. [12] stated that the core staffs in healthcare organizations are physicians and nurses and it would be of interest to observe how their attitudes toward the patient safety culture. Besides, physicians and nurses with different demographic variables might perceive the patient safety culture differently [12], [13]. Therefore, this study uses the internal patient safety culture data of the safety attitudes questionnaire in 2015 from a state-owned regional hospital in Changhua County, Taiwan to assess how both physicians and nurses perceive the patient safety culture in terms of six dimensions.

\section{Literature Review of Safety Attitudes Questionnaire}

Table 1. Thirty Questions in Safety Attitudes Questionnaire

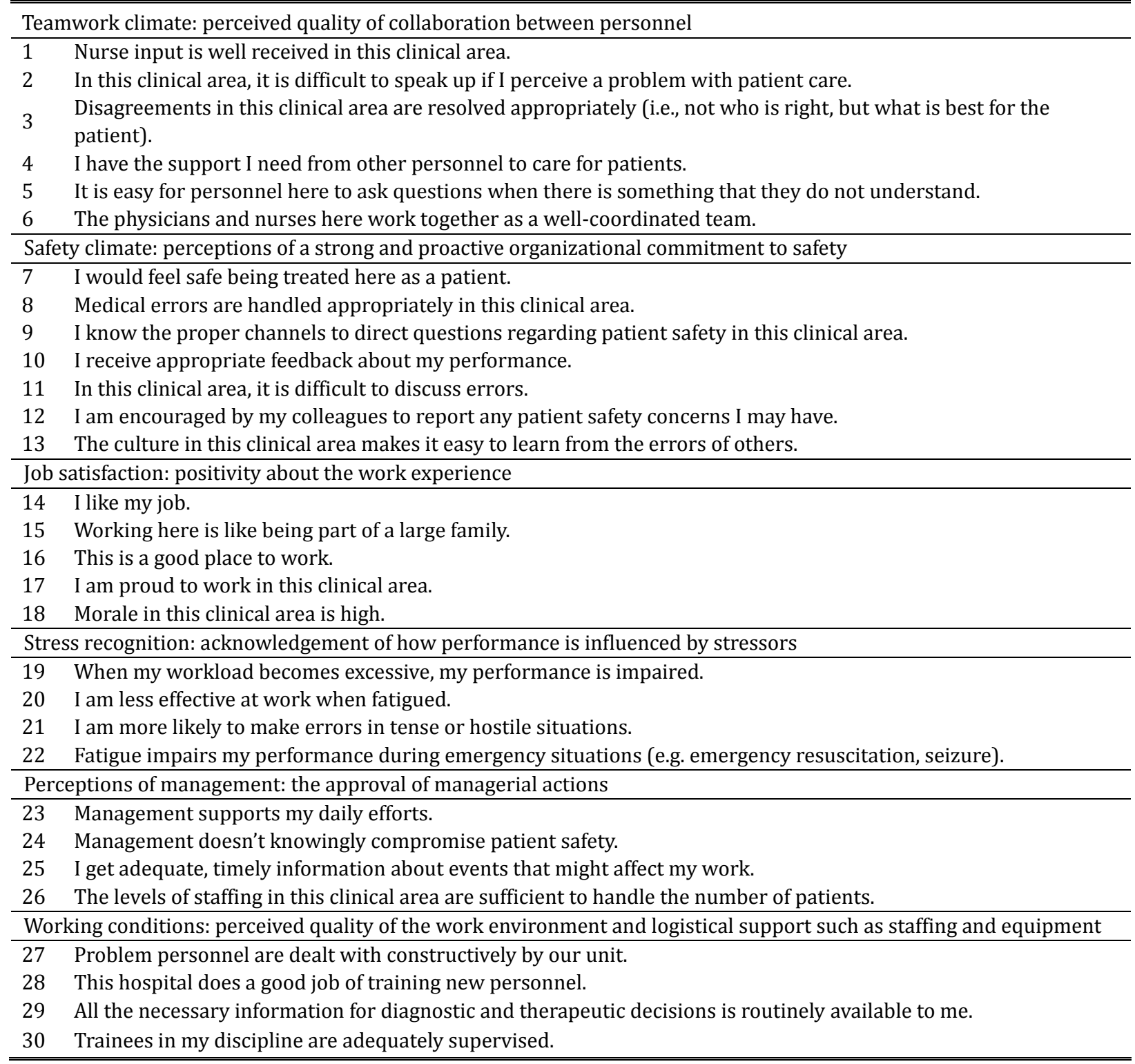


Sexton et al. [7] refined the intensive care unit management attitudes questionnaire to develop safety attitudes questionnaire based on the flight management attitudes questionnaire in 2006. There are six dimensions in the safety attitudes questionnaire including teamwork climate, safety climate, perceptions of management, job satisfaction, stress recognition, and working conditions [1], [10]. Besides, safety attitudes questionnaire has thirty questions as shown in Table 1, and each question uses a five-point Likert's scale ranging from strongly agree to strongly disagree [2]. Both physicians and nurses are required to fill out these thirty questions on a yearly basis [3]. Moreover, Items 2 and 11 are the reversed questions. Thus, each respondent's answer needs to be adjusted. That is, if the original answer is strongly agree in either Item 2 or Item 11, the numerical value of one should be used rather than the original numerical value of five [2].

\section{Research Method}

This study is intended to observe how physicians and nurses with different demographic variables at Chang Hua Hospital, Department of Health and Welfare, a state-owned regional hospital located in Changhua County, Taiwan, perceive the patient safety culture based on the SAQ internal survey results conducted from May 2015 to June 2015. By removing incomplete questionnaire, the number of the effective questionnaires is 268 , representing an effective rate of $84.8 \%$. The demographic variables in this study include gender, age, supervisor/manager, job position, job status, experience in organization, experience in position, education, and direct patient contact, and the frequencies are depicted in Table 2.

Table 2. Demographic Information of this State-Owned Regional Hospital

\begin{tabular}{|c|c|c|c|c|c|c|c|}
\hline \multicolumn{2}{|c|}{ Demographic variable } & \multirow{2}{*}{$\begin{array}{r}\text { Frequency } \\
42\end{array}$} & \multirow{2}{*}{$\begin{array}{r}\text { Percentage } \\
15.7\end{array}$} & & \multirow{2}{*}{$\begin{array}{r}\text { Frequency } \\
50\end{array}$} & \multirow{2}{*}{$\begin{array}{r}\text { Percentage } \\
18.7\end{array}$} \\
\hline \multirow{2}{*}{ Gender } & 1. Male & & & \multicolumn{2}{|c|}{$\begin{array}{l}\text { Demographic varlable } \\
\text { Sunervisor/ } 1 \text { Yes }\end{array}$} & & \\
\hline & 2. Female & 226 & 84.3 & Manager & 2. No & 218 & 81.3 \\
\hline \multirow{6}{*}{$\begin{array}{l}\text { Age (unit: } \\
\text { years old) }\end{array}$} & 1. Less than 20 & 0 & 0 & \multirow{2}{*}{ Job position } & 1. Physician & 44 & 16.4 \\
\hline & 2. $21-30$ & 84 & 31.3 & & 2. Nurse & 224 & 83.6 \\
\hline & 3. $31-40$ & 129 & 48.1 & \multirow{4}{*}{ Job status } & 1. Full time & 55 & 20.5 \\
\hline & 4. $41-50$ & 39 & 14.6 & & 2. Part time & 173 & 64.6 \\
\hline & 5. $51-60$ & 13 & 4.9 & & 3. Agency & 40 & 14.9 \\
\hline & 6. 61 and above & 3 & 1.1 & & 4. Contract & 0 & 0 \\
\hline \multirow{7}{*}{$\begin{array}{l}\text { Experience } \\
\text { in } \\
\text { organization } \\
\text { (unit: years) }\end{array}$} & 1. less than 0.5 & 12 & 4.5 & \multirow{7}{*}{$\begin{array}{r}\text { Experience } \\
\text { in positio } \\
n \\
\text { (unit: } \\
\text { years) }\end{array}$} & 1. less than 0.5 & 16 & 6.0 \\
\hline & 2. 0.5 to less than 1 & 25 & 9.3 & & 2. 0.5 to less & 29 & 10.8 \\
\hline & 3. 1 to 2 & 32 & 11.9 & & than 1 & 41 & 15.3 \\
\hline & 4. 3 to 4 & 39 & 14.6 & & 3.1 to 2 & 51 & 19.0 \\
\hline & 5.5 to 10 & 107 & 39.9 & & 4.3 to 4 & 91 & 34.0 \\
\hline & 6. 11 to 20 & 50 & 18.7 & & b. 5 to 10 & 37 & 13.8 \\
\hline & 7. 21 and more & 3 & 1.1 & & $\begin{array}{l}6.11 \text { to } 20 \\
7.21 \text { and more }\end{array}$ & 3 & 1.1 \\
\hline \multirow{6}{*}{ Education } & 1. Junior high & & & \multirow{6}{*}{$\begin{array}{l}\text { Direct } \\
\text { patient } \\
\text { contact }\end{array}$} & 1. No & 2 & 0.7 \\
\hline & school and below & & & & 2. Rare & 13 & 4.9 \\
\hline & 2. Senior high & 0 & 0 & & 3.Very often & 253 & 94.4 \\
\hline & school & 3 & 1.1 & & & & \\
\hline & 3. & 243 & 90.7 & & & & \\
\hline & $\begin{array}{l}\text { College/University } \\
\text { 4. Graduate school }\end{array}$ & 22 & 8.2 & & & & \\
\hline
\end{tabular}

The scale for each question in safety attitudes questionnaire ranges from one to five representing strongly disagree to strongly agree. To calculate the value for each dimension, the scores from the questions in each dimension are summed up. Independent sample t test for mean differences and one-way analysis of variance with $\alpha=0.05$ are used to analyze if different demographic variables perceive different patient safety culture in terms of dimensions. If the $p$-value is less than $\alpha=0.05$, Bonferroni method is used for post hoc analysis, except for gender, supervisor/manager, and job position with only two levels, because 
Bonferroni method reduces the probability of a Type I error outperforming Scheffe method [14].

\section{Results}

Tables 3-5 summarize how employees with different gender, supervisor/manager, or job position perceive the level of agreement (satisfaction) on six dimensions of the safety attitudes questionnaire. Specifically, males have higher satisfaction than females in teamwork climate, safety climate, job satisfaction, perceptions of management, and working conditions statistically. In addition, employees who are in charge of supervisors/managers are more satisfied statistically in teamwork climate, safety climate, job satisfaction, perceptions of management, and working conditions (with equal variance assumption). Furthermore, physicians have higher perceptions than nurses significantly in teamwork climate, safety climate, job satisfaction, perceptions of management, and working conditions.

Table 3. Mean Differences on Six Dimensions for Gender

\begin{tabular}{llrll}
\hline \multicolumn{1}{c}{ Dimension } & Assumption & $\mathrm{t}$ & Sig. & \multicolumn{2}{c}{ Post Hoc } \\
\hline \multirow{2}{*}{ Teamwork climate } & Equal variance & 4.029 & .000 & $1>2$ \\
& Unequal variance & 3.929 & .000 & $1>2$ \\
\hline \multirow{2}{*}{ Safety climate } & Equal variance & 3.542 & .000 & $1>2$ \\
& Unequal variance & 3.346 & .001 & $1>2$ \\
\hline \multirow{2}{*}{ Job satisfaction } & Equal variance & 4.085 & .000 & $1>2$ \\
& Unequal variance & 3.929 & .000 & $1>2$ \\
\hline \multirow{2}{*}{ Stress recognition } & Equal variance & 1.914 & .057 & \\
& Unequal variance & 1.895 & .063 & \\
\multirow{2}{*}{ Perceptions of management } & Equal variance & 4.039 & .000 & $1>2$ \\
& Unequal variance & .3954 & .000 & $1>2$ \\
\hline \multirow{2}{*}{ Working conditions } & Equal variance & 4.531 & .000 & $1>2$ \\
& Unequal variance & 4.347 & .000 & $1>2$ \\
\hline \hline
\end{tabular}

Table 4. Mean Differences on Six Dimensions for Supervisor/Manager

\begin{tabular}{lllll}
\hline \multicolumn{1}{c}{ Dimension } & Assumption & $\mathrm{t}$ & Sig. & Post Hoc \\
\hline \multirow{2}{*}{ Teamwork climate } & Equal variance & 3.698 & .000 & $1>2$ \\
& Unequal variance & 3.733 & .000 & $1>2$ \\
\hline \multirow{2}{*}{ Safety climate } & Equal variance & 4.110 & .000 & $1>2$ \\
& Unequal variance & 3.926 & .000 & $1>2$ \\
\hline \multirow{2}{*}{ Job satisfaction } & Equal variance & 2.568 & .011 & $1>2$ \\
& Unequal variance & 2.453 & .017 & $1>2$ \\
\hline \multirow{2}{*}{ Stress recognition } & Equal variance & 1.397 & .164 & \\
& Unequal variance & 1.362 & .177 & \\
\multirow{2}{*}{ Perceptions of management } & Equal variance & 2.996 & .003 & $1>2$ \\
& Unequal variance & 2.947 & .004 & $1>2$ \\
\hline \multirow{2}{*}{ Working conditions } & Equal variance & 2.162 & .031 & $1>2$ \\
& Unequal variance & 1.988 & .051 & \\
\hline \hline
\end{tabular}

Table 5. Mean Differences on Six Dimensions for Job Position

\begin{tabular}{|c|c|c|c|c|}
\hline Dimension & Assumption & $\mathrm{t}$ & Sig. & Post Hoc \\
\hline \multirow{2}{*}{ Teamwork climate } & Equal variance & 4.055 & .000 & $1>2$ \\
\hline & Unequal variance & 3.894 & .000 & $1>2$ \\
\hline \multirow{2}{*}{ Safety climate } & Equal variance & 3.471 & .001 & $1>2$ \\
\hline & Unequal variance & 3.273 & .002 & $1>2$ \\
\hline \multirow{2}{*}{ Job satisfaction } & Equal variance & 4.170 & .000 & $1>2$ \\
\hline & Unequal variance & 4.104 & .000 & $1>2$ \\
\hline \multirow{2}{*}{ Stress recognition } & Equal variance & 1.950 & .052 & \\
\hline & Unequal variance & 1.967 & .054 & \\
\hline \multirow{2}{*}{ Perceptions of management } & Equal variance & 3.902 & .000 & $1>2$ \\
\hline & Unequal variance & 3.886 & .000 & $1>2$ \\
\hline
\end{tabular}




\begin{tabular}{lllll}
\hline \multirow{2}{*}{ Working conditions } & Equal variance & 3.893 & .000 & $1>2$ \\
& Unequal variance & 3.881 & .000 & $1>2$ \\
\hline \hline
\end{tabular}

Table 6 provides that employees with different ages perceive teamwork climate, safety climate, job satisfaction, perceptions of management, and working conditions significantly different. From the descriptive statistics, employees who are more than 60 years old have the highest satisfaction in teamwork climate, job satisfaction, and working conditions, while employees who are 41-50 years old perceive the highest satisfaction in safety climate and perceptions of management. Besides, employees who are 41-50 years old have significantly better perceptions in teamwork climate, safety climate, job satisfaction, perceptions of management, and working conditions than employees who are 21-30 years old. Moreover, employees who are 41-50 years old have significantly better perceptions than employees with 31-40 years old in perceptions of management. That is, young employees tend to have less satisfaction than the elderly employees in most of the dimensions.

Table 6. ANOVA Results on Six Dimensions for Age

\begin{tabular}{llll}
\hline \multicolumn{1}{c}{ Dimension } & $\mathrm{t}$ & Sig. & Post Hoc \\
\hline Teamwork climate & 3.460 & .009 & $4>2$ \\
Safety climate & 3.202 & .014 & $4>2$ \\
Job satisfaction & 4.283 & .002 & $4>2$ \\
Stress recognition & 0.483 & .748 & \\
Perceptions of management & 4.879 & $.001 \quad 4>2,4>3$ & \\
Working conditions & 4.375 & $.002 \quad 4>2$ & \\
\hline \hline
\end{tabular}

Employees with different job status depicted in Table 7 have different perceptions in teamwork climate, safety climate, job satisfaction, stress recognition, and perceptions of management. Generally, full time employees tend to have the highest satisfaction, while part-time employees have the lowest satisfaction in the descriptive statistics. Moreover, full time employees have significant better perceptions in five out of six dimensions except for working conditions than part-time employees. Furthermore, full time employees are more satisfied than agency-based employees statistically in safety climate.

Table 7. ANOVA Results on Six Dimensions for Job Status

\begin{tabular}{llll}
\hline \hline \multicolumn{1}{c}{ Dimension } & $\mathrm{t}$ & \multicolumn{1}{c}{ Post Hoc } \\
\hline Teamwork climate & 9.091 & .000 & $1>2$ \\
Safety climate & 7.881 & .000 & $1>2,1>3$ \\
Job satisfaction & 3.607 & .028 & $1>2$ \\
Stress recognition & 3.716 & .026 & $1>2$ \\
Perceptions of management & 5.551 & .004 & $1>2$ \\
Working conditions & 2.965 & .053 & \\
\hline \hline
\end{tabular}

Employees with different experiences in organization only perceive working conditions statistically different with $\mathrm{p}=0.038$. However, further analyses do not show any significant differences. In addition, employees with different experiences in position have very similar results with different experiences in organization. That is, working conditions is the only dimension statistically different with $p=0.010$ when employees have different experiences in position. Besides, no significant difference exists among different experiences in position when the post hoc analysis is performed.

Employees with different educations have statistically different perceptions in teamwork climate, safety climate, job satisfaction, perceptions of management, and working conditions depicted in Table 8. Employees with graduate degrees have the highest satisfaction while employees with senior high school degrees have the lowest satisfaction by the descriptive statistics. The post hoc analysis shows that employees with graduate degrees perceive significantly better than employees with senior high school and 
college/university degrees in four out of six dimensions. Finally, employees with different levels of direct patient contacts do not perceive significantly in these six dimensions.

Table 8. ANOVA Results on Six Dimensions for Education

\begin{tabular}{lrrl}
\hline \hline \multicolumn{1}{c}{ Dimension } & $\mathrm{t}$ & Sig. & \multicolumn{1}{c}{ Post Hoc } \\
\hline Teamwork climate & 11.406 & .000 & $3>2,4>2,4>3$ \\
Safety climate & 5.706 & .004 & $4>3$ \\
Job satisfaction & 5.934 & $.003 \quad 4>2,4>3$ \\
Stress recognition & 0.666 & .515 & \\
Perceptions of management & 9.444 & $.000 \quad 4>2,4>3$ \\
Working conditions & 5.921 & $.003 \quad 4>2,4>3$ \\
\hline \hline
\end{tabular}

From Table 9, gender, age, supervisor/manager, job position, job status, and education are the critical demographic variables that have significant impacts for at least four out of six dimensions. In contrast, teamwork climate, safety climate, job satisfaction, perceptions of management, and working conditions are influenced by six out of nine demographic variables. From the managerial viewpoints, the hospital management needs to pay much attention to these critical demographic variables in order to improve the patient safety culture.

Table 9. The Relationship between Dimensions and Demographic Variables

\begin{tabular}{lccccccccc}
\hline \hline & Gender & Age & $\begin{array}{c}\text { Supervisor/ } \\
\text { Manager }\end{array}$ & $\begin{array}{c}\text { Job } \\
\text { Position }\end{array}$ & $\begin{array}{c}\text { Job } \\
\text { Status }\end{array}$ & $\begin{array}{c}\text { Experience } \\
\text { in } \\
\text { Organization }\end{array}$ & $\begin{array}{c}\text { Experience } \\
\text { in Position }\end{array}$ & Education & $\begin{array}{c}\text { Direct } \\
\text { Patient } \\
\text { Contact }\end{array}$ \\
\hline Teamwork climate & $*$ & $*$ & $*$ & $*$ & $*$ & & & $*$ & \\
Safety climate & $*$ & $*$ & $*$ & $*$ & $*$ & & & $*$ & \\
Job satisfaction & $*$ & $*$ & $*$ & $*$ & $*$ & & & $*$ \\
Stress recognition & & & & & $*$ & & & $*$ \\
Perceptions of & $*$ & $*$ & $*$ & $*$ & $*$ & & & $*$ \\
management & $*$ & $*$ & & $*$ & & $*$ & $*$ & $*$ \\
Working conditions & $*$ & & & $*$ & & & $*$ \\
\hline \hline
\end{tabular}

\section{Conclusions}

This study is to examine how physicians and nurses perceive the patient safety culture in terms of dimensions based on the safety attitudes questionnaire in 2015 from a state-owned regional hospital in Changhua County, Taiwan. Demographic variables including gender, age, job position, job status, and education play important roles to influence five out of six dimensions of the patient safety culture. On the other hand, teamwork climate, safety climate, job satisfaction, perceptions of management, and working conditions are the more critical dimensions to be taken into account because these five dimensions are affected by six out of nine demographic variables. In order to relentlessly improve the patient safety culture in this state-owned regional hospital, the hospital management needs to pay much attention to critical demographic variables, identify those employees who have statistically lower perceptions in terms of dimensions, and then take actions to address the deficiencies.

\section{Acknowledgment}

This study is supported financially by Chang Hua Hospital, Department of Health and Welfare, Changhua County, Taiwan with the grant number of 106-3.

\section{References}

[1] Wu, Y., Fujita, S., Seto, K., Ito, S., Matsumoto, K., Huang, C.-C., \& Hasegawa, T. (2013). The impact of nurse 
working hours on patient safety culture: A cross-national survey including Japan, the United States and Chinese Taiwan using the Hospital Survey on Patient Safety Culture. BMC Health Services Research, 13, 394.

[2] Lee, Y.-C., Huang, C.-H., Hsu, C.-Y., \& Wu, H.-H. (2016). A longitudinal study of assessing the patient safety culture from nurses' viewpoints based on the safety attitudes questionnaire in Taiwan. International Journal of Innovation, Management and Technology, 7(6), 266-271.

[3] Lee, Y.-C., Huang, C.-H., \& Wu, H.-H. (2016). A case study of using importance-agreement analysis to analyze patient safety culture based on the safety attitudes questionnaire in Taiwan. International Journal of Innovation, Management and Technology, 7(5), 213-218.

[4] Chen, C., \& Li, H. H. (2010). Measuring patient safety culture in Taiwan using the hospital survey on patient safety culture (HSOPSC). BMC Health Services Research, 10, 152.

[5] Aghdash, S. A., Ebadi-fard Azar, F., Rezapour, A., Mirnia, K., Azami, A., \& Saadati, M. (2014). Patient safety culture: A meta-analysis of hospitals data. International Journal of Hospital Research, 3(4), 209-217.

[6] Bodur, S., \& Filiz, E. (2010). Validity and reliability of Turkish version of 'hospital survey on patient safety culture' and perception of patient safety in public hospitals in Turkey. BMC Health Services Research, 10, 28.

[7] Sexton, J. B., Helmreich, R. L., Neilands, T. B., Rowan, K., Vella, K., Boyden, J., Roberts, P. R., \& Thomas, E. J. (2006). The safety attitudes questionnaire: Psychometric properties, benchmarking data, and emerging research. BMC Health Services Research, 6, 44.

[8] Zimmermann, N., Küng, K., Sereika, S. M., Engberg, S., Sexton, B., \& Schwendimann, R. (2013). Assessing the safety attitudes questionnaire (SAQ), German language version in Swiss University Hospitals - A validation study. BMC Health Services Research, 13, 347.

[9] Gabrani, A., Hoxha, A., Simaku, A., \& Gabrani, J. (2015). Application of the safety attitudes questionnaire (SAQ) in Albanian hospitals: A cross-sectional study. BMJ Open, 5, e006528.

[10] Lee, Y. C., Wu, H. H., Hsieh, W. L., Weng, S. J., Hsieh, L. P., \& Huang, C. H. (2015). Applying importance-performance analysis to patient safety culture. International Journal of Health Care Quality Assurance, 28(8), 826-840.

[11] Agnew, C., Flin, R., \& Mearns, K. (2013). Patient safety climate and worker safety behaviours in acute hospitals in Scotland. Journal of Safety Research, 45, 95-101.

[12] Lee, Y. C., Weng, S. J., Huang, C. H., Hsieh, W. L., \& Wu, H. H. (2016). Analyzing emotional exhaustion from viewpoints of physicians and nurses - A case of a regional teaching hospital. TEM Journal, 5(2), 231-235.

[13] Lee, Y. C., Huang, S. C., Huang, C. H., \& Wu, H. H. (2016). A new approach to identify high burnout medical staffs by kernel k-means cluster analysis in a regional teaching hospital in Taiwan. Inquiry, 53, 0046958016679306.

[14] McHugh, M. L. (2011). Multiple comparison analysis testing in ANOVA. Biochemia Medica, 21(3), 203-209.

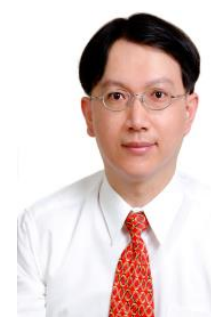

Hsin-Hung Wu is a university distinguished professor at National Changhua University of Education (NCUE), Changhua, Taiwan since August 2014. He is with the Department of Business Administration at NCUE since August 2004. Dr. Wu received his Ph.D. degree in the Department of Industrial \& Systems Engineering and Engineering Management at University of Alabama in Huntsville, Huntsville, AL, USA in May 1998. His research interests include service quality, patient safety, decision analysis, data mining, and applied statistics. He has published more than 140 journal papers and 200 conference papers. 


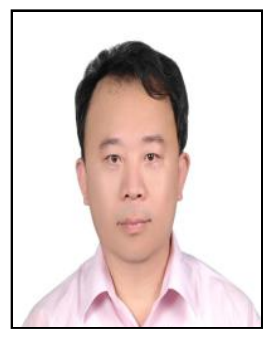

Jiunn-I Shieh graduated in physics from National Taiwan University, Taiwan. He obtained his PhD of mathematics from the University of Texas at Austin, USA. He is a professor in the Department of M-Commerce and Multimedia Applications at Asia University and the Department of Dental Hygiene at China Medical University.

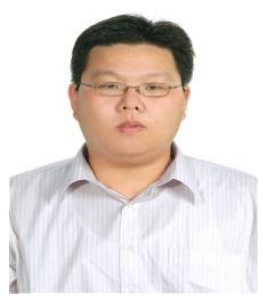

Kuan-Kai Huang graduated in the Department of Computer Science and Information Engineering, Asia University, Taiwan. He obtained his $\mathrm{PhD}$ of information engineering from the Asia University, Taiwan. His major research interest is service quality. He is a senior specialist in the Center for Quality Management, Chang Hua Hospital.

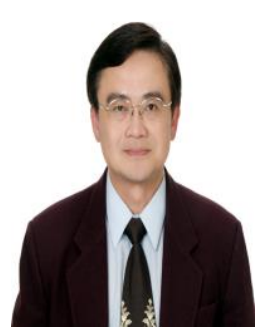

Wen-Huai Hsieh was born at Chiayi County of Taiwan on 15th October 1956, who finished the 7-year learning course and graduated from School of Medicine of National Yang-Ming University in Taipei, Taiwan in 1983 and received the Doctor's Degree of Medicine. Superintendent Hsieh received his Master's Degree of Management Information Systems from the Institute of Information Management of National Chung Cheng University at Chiayi County of Taiwan in 2004. Currently, he is the superintendent of Changhua hospital, Ministry of Health and Welfare since August 2014 and was the vice superintendent of Nantou hospital, Ministry of Health and Welfare from July 2012 to August 2014.

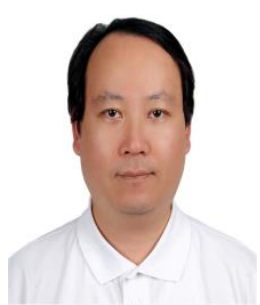

Shuo-Yen Ting graduated from School of Medicine, National Yang-Ming University in 1993, is a certified psychiatrist with 23-year clinical experiences. He has been chief of the Department of Psychiatry, Chang Hua hospital, an affiliated hospital of Ministry of Health and Welfare in Taiwan for 15 years. In 2007, he established the largest Methadone Maintenance Therapy program in central Taiwan providing service to more than five hundred enrolled members every day. He received his Master of Science at National Taiwan University in 2010 and Master of Public Health at Harvard School of Public Health, USA in 2012. He concentrated his study in health policy and management in both master's degree programs. In October, 2012, he helped establish Center for Quality Management in Chang Hua Hospital and lead a 4-fulltime-member team as the director of the inter-disciplinary center. His main efforts include building patient safety report system, quality improvement projects and activities, patient-centered medical service, and health indicator monitoring. He has been awarded one of "The Excellent Doctors" in Ministry of Health and Welfare in 2014 and "The Outstanding Contribution to Medicine Award" in Changhua County in 2012. He currently leads two teams introducing Psychodrama and Mindfulness-Based Cognitive Therapy for depression to the staffs and patients as parts of the "Health Promotion Hospital" Project.

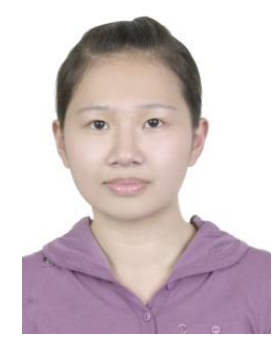

Jy-Wun Chen graduated in nursing and management from Jen-Teh Junior College of Medicine. Ms. Chen has worked as a project manager of Patient Safety and Medical Quality with outstanding performance in Center for Quality Management, Chang Hua Hospital for six years. 